\title{
First demonstration of the influence of photoperiod on the thermal requirements for development in insects and in particular the linden-bug, Pyrrhocoris apterus (Heteroptera: Pyrrhocoridae)
}

\author{
Elena B. LOPATINA ${ }^{1}$, Sergei V. BALASHOV² and Vladilen E. KIPYATKOV ${ }^{2}$ \\ ${ }^{1}$ Laboratory of Entomology, Biological Research Institute of St. Petersburg University, 2 Oranienbaumskoye shosse, Petergof, \\ St. Petersburg, 198904, Russia; e-mail: elena.lopatina@gmail.com \\ ${ }^{2}$ Department of Entomology, Faculty of Biology and Soil Sciences, St. Petersburg State University, 7/9 Universitetskaya nab., \\ St. Petersburg, 199034, Russia
}

Key words. Heteroptera, Pyrrhocoridae, Pyrrhocoris apterus, photoperiod, temperature, thermal reaction norms, thermal requirements for development, development time, development rate, thermal threshold, thermal lability, seasonal variation

\begin{abstract}
The influence of photoperiod on the thermal requirements for development was discovered for the first time in insects during experiments on the linden-bug, Pyrrhocoris apterus. The effect of photoperiod on the duration of linden-bug development at five constant temperatures $\left(20,22,24,26\right.$ and $\left.28^{\circ} \mathrm{C}\right)$ was measured and the thermal requirements for development at three photoperiods (14, 17 and $20 \mathrm{~h}$ light per day) were calculated. Bugs from four geographic populations were used in these experiments: Pyatigorsk $\left(44^{\circ} 02^{\prime} \mathrm{N}, 43^{\circ} 04^{\prime} \mathrm{E}\right)$, Borisovka $\left(50^{\circ} 36^{\prime} \mathrm{N}, 36^{\circ} 01^{\prime} \mathrm{E}\right)$, Mikhailov $\left(54^{\circ} 15^{\prime} \mathrm{N}, 39^{\circ} 0^{\prime} \mathrm{E}\right)$ and Ryazan $\left(54^{\circ} 36^{\prime} \mathrm{N}, 39^{\circ} 42^{\prime} \mathrm{E}\right)$. From the values of individual development times at different temperatures the coefficient of linear regression of development rate (the inverse of the duration) on temperature and the thermal threshold for development were calculated. Both these parameters were found to decrease significantly with decrease in day-length for all four populations studied. It means that at shorter day-lengths nymphal development is less dependent on temperature compared to the development at longer day-lengths. These effects seem to be adaptive. The development times of nymphs at relatively high temperatures (above $24-25^{\circ} \mathrm{C}$ ) are shorter under long-days than under short days which should be advantageous at the height of summer when the days are long and the weather is warm. In the contrast, at relatively low temperatures (below $24-25^{\circ} \mathrm{C}$ ) the nymphs develop significantly faster under short-days than under long days, which is advantageous at the end of summer as it allows the nymphs to reach the adult stage, the only stage capable of overwintering. The influence of photoperiod on the thermal reaction norm appeared to be more or less gradual, i.e. the shorter the day-length the shallower the slope of the regression line of development rate on temperature and the lower the thermal threshold for development. An analysis of the literature shows that this effect of photoperiod on the thermal requirements for development is widespread among insects but has been overlooked by previous authors. The authors conclude that the variation in the development time observed in insects at different seasons, photoperiods or food regimes, or from different populations, etc., are generally due to some modification of the thermal reaction norms and more specifically to differences in the thermal requirements for development.
\end{abstract}

\section{INTRODUCTION}

The rate of growth and development of insects is usually regulated by direct influence of temperature but can also depend on other factors that act indirectly and serve as seasonal cues inducing or terminating diapause. One of the most important cues is photoperiod. More than 80 species of insects from 10 orders are now known to modify the rates of larval development in response to photoperiods. Using the generalizations given by Danks (1987) it is possible to classify all these species into 3 groups in which:

(1) Short days retard development compared to long days;

(2) Short days accelerate development compared to long days;

(3) Intermediate photoperiods (which are as a rule close to the critical day-length) retard or accelerate development compared to short and long day conditions.

According to Musolin \& Saulich (1997) all three types of photoperiodic control of development mentioned above are found in bugs. This was confirmed recently
(Nakamura, 2002; Musolin \& Numata, 2003). However, the second type (the acceleration of development under short days compared to long days) is much more widespread. In some bug species photoperiod does not influence the duration of development.

In the linden-bug, Pyrrhocoris apterus, the winter diapause of adults is controlled by a long-day photoperiodic response (Volkovich \& Goryshin, 1978; Numata et al., 1993). Saunders (1983) found that $P$. apterus nymphs develop faster under short-day than long-day conditions but the longest development is observed under intermediate photoperiods close to the critical one. He studied linden-bugs from Prague and used only one temperature $\left(24^{\circ} \mathrm{C}\right)$ and several photoperiodic regimes. Later Numata and his co-authors investigated this phenomena in more detail in linden-bugs from Borisovka, Belgorod prov., Russia, using three constant temperatures and five photoperiods. Their results were similar: nymphal development is accelerated by short compared to long-day photoperiods and retarded when reared under photoperiods close to the critical day length (Numata et al., 1993). 
TABLE 1. The overall experimental design, the mean temperatures recorded and the number of linden-bug nymphs that survived in the experiment.

\begin{tabular}{|c|c|c|c|c|c|}
\hline \multirow[t]{2}{*}{$\begin{array}{l}\text { Photoperiod } \\
\mathrm{L}: \mathrm{D}(\mathrm{h}) \\
\end{array}$} & \multirow{2}{*}{$\begin{array}{c}\begin{array}{c}\text { Set temperature } \\
\left({ }^{\circ} \mathrm{C}\right)\end{array} \\
2003\end{array}$} & \multirow[t]{2}{*}{$\begin{array}{c}\text { Mean temperature } \\
\left({ }^{\circ} \mathrm{C}\right)\end{array}$} & \multicolumn{3}{|c|}{$\begin{array}{l}\text { Number of individuals that survived } \\
\text { in each experiment }\end{array}$} \\
\hline & & & Ryazan & Mikhailov & Pyatigorsk \\
\hline \multirow{5}{*}{$20: 4$} & 20 & 20.18 & 39 & 94 & 39 \\
\hline & 22 & 21.96 & 26 & 78 & 6 \\
\hline & 24 & 23.87 & 54 & 150 & 86 \\
\hline & 26 & 25.72 & 70 & 244 & 71 \\
\hline & 28 & 27.74 & 147 & 216 & 117 \\
\hline \multirow{5}{*}{$14: 10$} & 20 & 19.85 & 23 & 31 & 50 \\
\hline & 22 & 21.81 & 14 & 81 & 41 \\
\hline & 24 & 24.36 & 97 & 47 & 50 \\
\hline & 26 & 25.89 & 69 & 57 & 95 \\
\hline & 28 & 28.62 & 90 & 168 & 93 \\
\hline \multicolumn{3}{|c|}{2004} & \multicolumn{3}{|c|}{ Borisovka } \\
\hline \multirow{4}{*}{$20: 4$} & 22 & 21.73 & & 29 & \\
\hline & 24 & 23.53 & & 38 & \\
\hline & 26 & 25.66 & & 48 & \\
\hline & 28 & 27.95 & & 5 & \\
\hline \multirow{5}{*}{$17: 7$} & 20 & 20.01 & & 9 & \\
\hline & 22 & 22.00 & & 43 & \\
\hline & 24 & 23.79 & & 19 & \\
\hline & 26 & 26.01 & & 11 & \\
\hline & 28 & 28.02 & & 76 & \\
\hline \multirow{5}{*}{$14: 10$} & 20 & 19.97 & & 4 & \\
\hline & 22 & 21.77 & & 58 & \\
\hline & 24 & 23.91 & & 24 & \\
\hline & 26 & 25.65 & & 13 & \\
\hline & 28 & 27.85 & & 38 & \\
\hline
\end{tabular}

The authors of most papers revealed and discussed the evident differences in the development times of insects kept under different photoperiodic conditions. However, dissimilarities in the thermal requirements for development at different photoperiods were not recorded. Only one paper records the parameters of the linear regression of the development rate on temperature under long and short day conditions, and that is for the bug Dolycoris baccarum (Nakamura, 2002). Unfortunately, the author did not comment on or discuss the slight differences in the values of the thermal thresholds and the regression coefficients estimated for different photoperiods.

In the course of our extensive study of intraspecific variation in the thermal reaction norms for development in insects we revealed seasonal variation in the thermal requirements for pupal development in Myrmica ants (Kipyatkov et al., 2005). The existence of such seasonal changes and the critical analysis of the literature inspired us to suppose that some seasonal cues, e.g. photoperiod, might affect the thermal reaction norms for insect development. Therefore, the main goal of our study was to answer the following questions: (1) Do insects developing at different day-lengths have different thermal requirements for development? (2) Can photoperiod make development more or less temperature dependent, that is, alter the coefficient of linear regression of development rate on temperature (i.e., the slope of the regression line) and the thermal threshold for development?

\section{MATERIAL AND METHODS}

Adult linden-bugs were collected in four geographic regions:

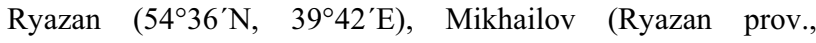
$54^{\circ} 15^{\prime} \mathrm{N}, 39^{\circ} 0^{\prime} \mathrm{E}$ ), Pyatigorsk (Krasnodar prov., $44^{\circ} 02^{\prime} \mathrm{N}$, $43^{\circ} 04^{\prime} \mathrm{E}$ ) and Borisovka (Belgorod prov., $\left.50^{\circ} 36^{\prime} \mathrm{N}, 36^{\circ} 01^{\prime} \mathrm{E}\right)$. In Borisovka the bugs were collected from the same local population which was used by earlier authors (Volkovich, Goryshin, 1978; Numata et al., 1993). In Ryazan, Mikhailov and Pyatigorsk the bugs were collected in autumn 2002 and hibernated in the laboratory for 4 months at $3-5^{\circ} \mathrm{C}$. The experiments were started in spring 2003. In Borisovka the bugs were collected in spring 2004, just after hibernation, and experiments started immediately.

The stock cultures of reproductive linden-bugs were kept at $24^{\circ} \mathrm{C}$ and a $20 \mathrm{~h}$ photoperiod. Each pair (a female and a male) was maintained separately in a plastic Petri dish (diam $60 \mathrm{~mm}$ ). Their progeny were kept in plastic containers. Smaller containers (vol. $200 \mathrm{ml}$ ) were used to keep from 20 to 30 nymphs and larger ones (vol. $500 \mathrm{ml}$ ) for 30 to 60 nymphs. Linden-tree fruits were used as food for adult bugs from Borisovka and their nymphs. Other bugs and their nymphs were fed with sunflower seeds. Plastic tubes filled with water and covered with cotton plugs were put in each container to provide water for the insects.

The eggs laid by females were collected twice a day (in the morning and in the evening) and randomly distributed between different experimental regimes. Bugs from all the populations were reared at five constant temperatures $(20.0 \pm 0.5,22.0 \pm$ 
$0.5,24.0 \pm 0.5,26.0 \pm 0.5$ and $28.0 \pm 0.5^{\circ} \mathrm{C}$ ) in combination with two photoperiods - a long day (LD) of $20 \mathrm{~h}$ and a short day (SD) of $14 \mathrm{~h}$ for all populations. An additional intermediate daylength (ID) of $17 \mathrm{~h}$, which is close to the critical day-length of the photoperiodic response, was used for rearing the Borisovka population (the critical day-length for this population is $17.5 \mathrm{~h}$ according to Volkovich \& Goryshin, 1978).

Tinytalk ${ }^{\circledR}$ II Data Loggers (Gemini Data Loggers LTD) were used to measure the temperature in experimental photothermostats. The data loggers recorded the temperature with an accuracy of $\pm 0.2^{\circ} \mathrm{C}$ every hour and stored the readings in the memory. After the experiment the data collected were offloaded into a computer and the mean temperature for each experimental regime was calculated (Table 1 ).

The cultures with eggs were checked twice a day (in the morning and in the evening) in order to determine the time when the nymphs hatched more accurately since the eggs of the linden bug develop rather fast $\left(6\right.$ days at $28^{\circ} \mathrm{C}$ and 14 days at $20^{\circ} \mathrm{C}$ according to our data). The cultures with nymphs were observed once a day in order to determine the development time (D) from hatching to adult emergence.

The data were analysed on a computer using Quattro Pro 7.0 (C) 1996 Corel Corporation Ltd). The rate of development $(R)$ at a given temperature $(T)$ was calculated for each individual as $R_{T}$ $=1 / D$. The relationship between development rate and temperature in insects and many other poikilotherms is curvilinear at extreme temperatures, but over moderate temperatures it is approximately linear. This feature allows the calculation of the coefficient of linear regression (CLR) of development rate on

\section{A. Ryazan}

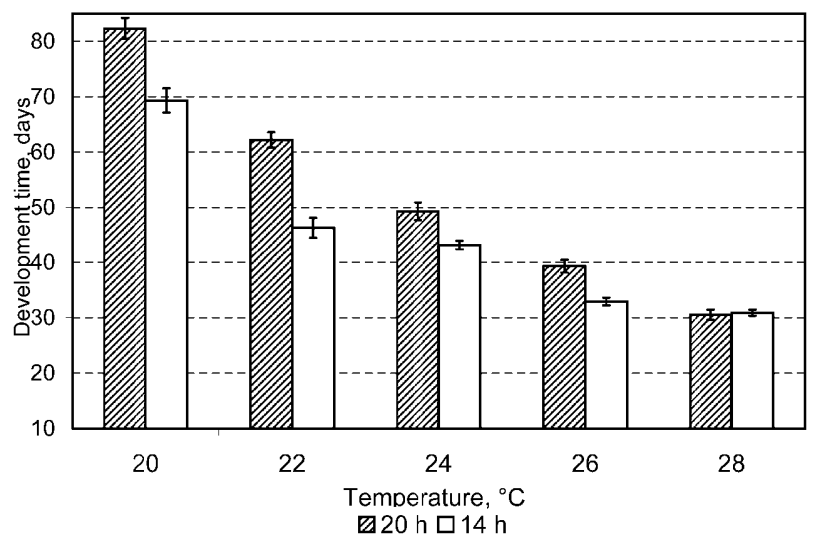

B. Mikhailov

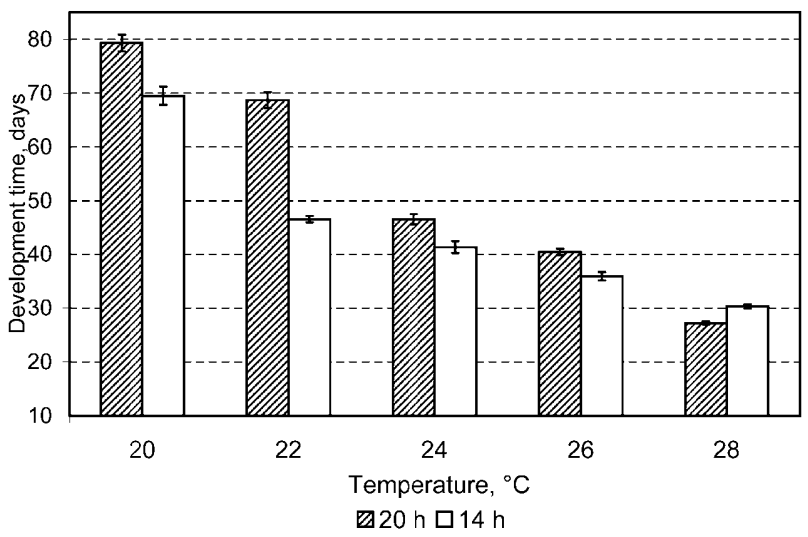

temperature (the slope of the regression line), the so-called lower developmental threshold or thermal threshold for development (TTD) - the theoretical minimum temperature at which development will proceed assuming a linear relationship between development rate and temperature, and the sum of effective temperatures (SET) or the number of day-degrees above thermal threshold needed to complete development (Campbell et al., 1974; Ratte, 1985). The TTD and SET are widely used and important life-history traits, especially in comparative studies of the adaptations of insect species and populations to local environmental conditions (Campbell et al., 1974; Lamb et al., 1987; Tauber et al., 1987, 1988; Honěk \& Kocourek, 1990; Honěk, 1996a,b). This is why linear regression analysis was used in this study. However, we prefer to use CLR instead of SET because the first is a direct measure of the slope of the regression line and thus characterises the dependence of development on temperature, which is more important in the context of this study. It seems unnecessary to use both these parameters since SET is the reverse of CLR (Campbell et al., 1974).

Assuming a linear relationship between development rate and temperature over the restricted temperature range used $\left(20-28^{\circ} \mathrm{C}\right)$ two coefficients of the linear equation were estimated using regression analysis:

$$
R_{\mathrm{T}}=a+b T
$$

where $a$-intercept, $b$ - slope (i.e., the CLR of development rate on temperature). The value TTD was estimated by extrapolating the regression line to $R_{T}=0$, thus TTD $=-a / b$. The standard errors (SE) of the intercept and slope were obtained from the

\section{Pyatigorsk}

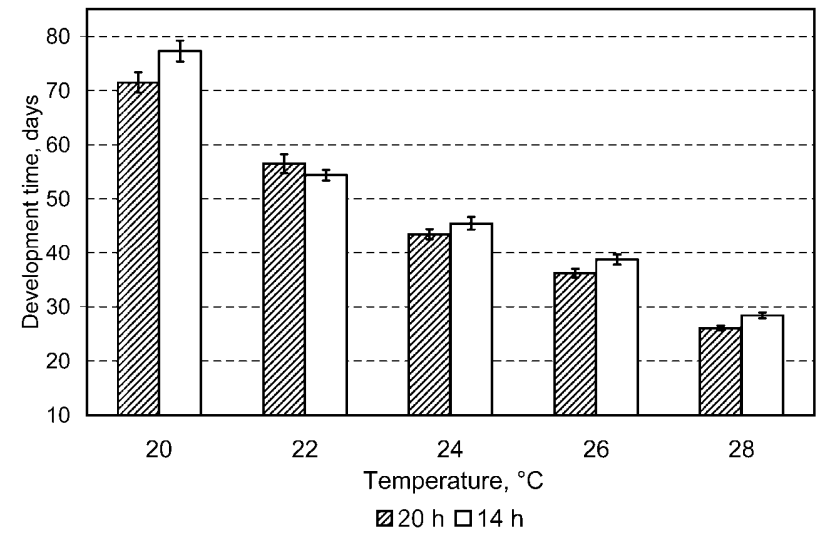

D. Borisovka

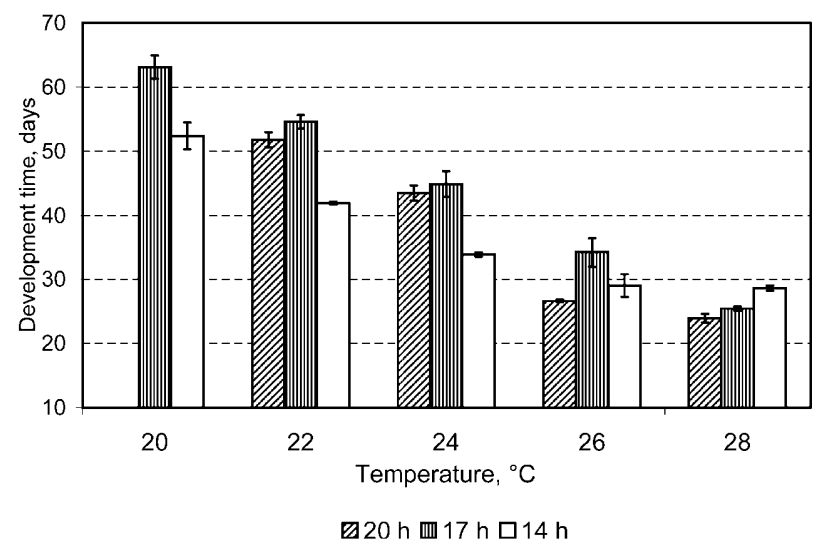

Fig. 1. Mean development times of Pyrrhocoris apterus nymphs from four geographic regions reared under different temperature and photoperiodic conditions. Vertical bars - standard errors of means. The numbers of individuals that survived in each experiment are given in Table 1. 
TABLE 2. Parameters of linear regression of development rate on temperature and the values of the thermal threshold for development of linden-bug nymphs from four geographic regions reared under different photoperiods.

\begin{tabular}{|c|c|c|c|c|c|c|c|c|}
\hline \multirow{2}{*}{ Region } & \multirow{2}{*}{$\begin{array}{c}\text { Photoperiod } \\
\text { L : D }\end{array}$} & \multirow{2}{*}{$\begin{array}{l}\text { Number } \\
\text { of nymphs }\end{array}$} & \multicolumn{4}{|c|}{ Parameters of linear regression of development rate on temperature $\left(\times 10^{-2}\right)$} & \multirow{2}{*}{ TTD } & \multirow{2}{*}{$\begin{array}{l}\text { SE of } \\
\text { TTD }\end{array}$} \\
\hline & & & Intercept & SE of intercept & Slope & SE of slope & & \\
\hline \multirow{2}{*}{ Ryazan } & $20: 4$ & 336 & -6.165 & 1.114 & 0.3551 & 0.0232 & 17.41 & 0.55 \\
\hline & $14: 10$ & 293 & -2.611 & 0.481 & 0.2101 & 0.0109 & 12.41 & 0.70 \\
\hline \multirow{2}{*}{ Mikhailov } & $20: 4$ & 782 & -5.542 & 0.525 & 0.3272 & 0.0076 & 17.02 & 0.19 \\
\hline & $14: 10$ & 384 & -2.222 & 0.455 & 0.1962 & 0.0074 & 11.32 & 0.55 \\
\hline \multirow{3}{*}{ Pyatigorsk } & $20: 4$ & 319 & -5.653 & 0.523 & 0.3403 & 0.0118 & 16.63 & 0.31 \\
\hline & $14: 10$ & 329 & -3.853 & 0.491 & 0.2573 & 0.0089 & 14.93 & 0.36 \\
\hline & $20: 4$ & 120 & -7.984 & 0.343 & 0.4504 & 0.0178 & 17.74 & 0.26 \\
\hline \multirow[t]{2}{*}{ Borisovka } & $17: 7$ & 158 & -5.564 & 0.422 & 0.3394 & 0.0116 & 16.44 & 0.32 \\
\hline & $14: 10$ & 137 & -1.884 & 0.344 & 0.1984 & 0.0112 & 9.54 & 0.84 \\
\hline
\end{tabular}

Slope - the coefficient of the linear regression of development rate on temperature (CLR); TTD - thermal threshold for development $\left({ }^{\circ} \mathrm{C}\right)$. The values for the intercept, slope and TTD calculated for nymphs from the same population reared at different photoperiods are significantly different $(t$-test) if marked with the same number $(\mathrm{p}<0.01-0.001)$.

regression analysis, the SE of the TTD values were calculated using the formula given by Campbell et al. (1974).

Statistical analyses was carried out using Statistica 5.5 (C) 1984-1999 by StatSoft, Inc.). In most experiments, the development times of the nymphs were not normally distributed and/or there were significant correlations between means and variances. The log (or log-log) transformation did not improve normality and/or eliminate the correlation between means and variances in most cases. Consequently, nonparametric statistics were used (Kruskal-Wallis ANOVA by Ranks test) for all comparisons of development times of the nymphs. The $t$-test for

\section{A. Ryazan}

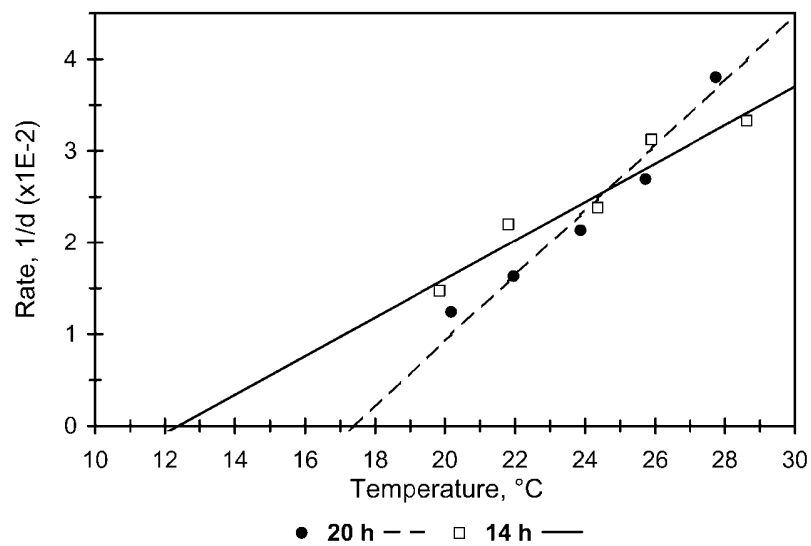

\section{Pyatigorsk}

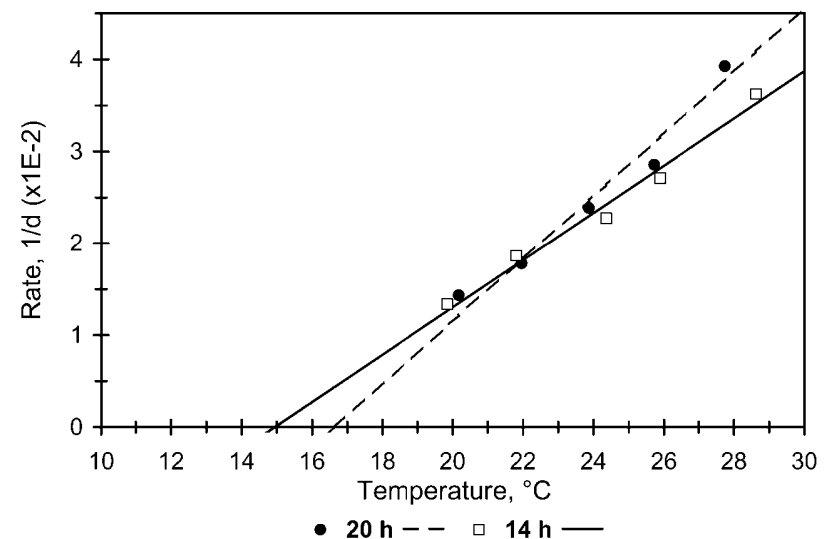

D. Borisovka
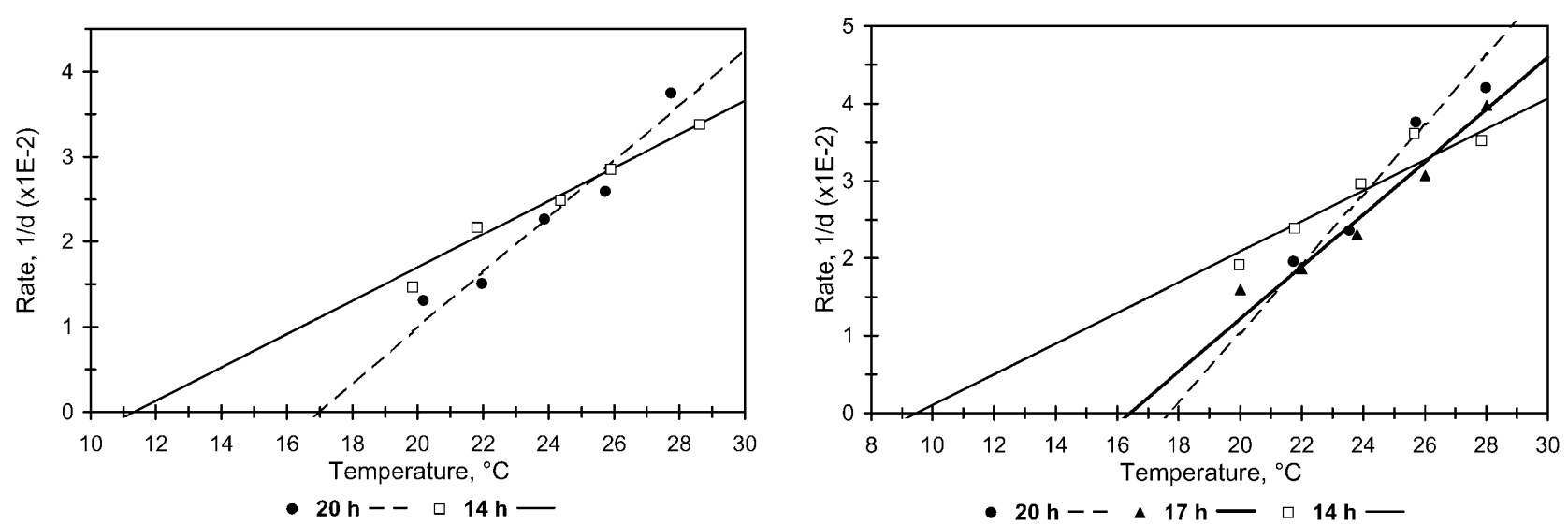

Fig. 2. Regression lines for development rate of nymphs of Pyrrhocoris apterus on temperature when reared under two different photoperiods. A - Ryazan population; B - Mikhailov population; C - Pyatigorsk population; D - Borisovka population. The numbers of individuals that survived in each experiment given in Table 1. 
independent samples was used to compare intercepts, regression coefficients and TTD values.

\section{RESULTS}

\section{Development times}

The photoperiod strongly influenced the duration of nymphal development (Fig. 1). This influence was significant for all four populations (Kruskal-Wallis test: $H=$ 3.54-21.8, $p<0.05-0.001)$. On average nymphs from Ryazan and Mikhailov developed significantly faster under short days $(14 \mathrm{~h})$ than long days $(20 \mathrm{~h})$ at all temperatures except $28^{\circ} \mathrm{C}$. In contrast, the mean development times of nymphs from the Pyatigorsk population were clearly longer under $14 \mathrm{~h}$ than $20 \mathrm{~h}$ at all temperatures except $22^{\circ} \mathrm{C}$ (Fig. 1). Similar to the nymphs from Ryazan and Mikhailov those from Borisovka developed much faster under short $(14 \mathrm{~h})$ than very long $(20 \mathrm{~h})$ days at 22 and $24^{\circ} \mathrm{C}$. However, the nymphs from Borisovka showed a distinct retardation of development when reared under an intermediate photoperiod $(17 \mathrm{~h})$ at all temperatures except $28^{\circ} \mathrm{C}$ (Fig. 1).

\section{Thermal requirements for development}

The parameters of the linear regression of development rate on temperature and the values of the thermal threshold for development (TTD) calculated for linden-bug nymphs from three geographic regions reared under different photoperiodic conditions are given in Table 2, and the corresponding regression lines are depicted in Fig. 2. It is obvious from these graphs that the dependence of nymphal development on temperature under long-day $(20 \mathrm{~h})$ conditions is characterized by substantially higher values of TTD and of the slope, i.e. of the coefficient of linear regression of development rate on temperature (CLR) compared with development under short-day $(14 \mathrm{~h})$ conditions. The values of TTD and CLR for the development of nymphs from Borisovka reared under the $17 \mathrm{~h}$ day-length appeared to be intermediate between those estimated for bugs reared under long or short day conditions (Fig. 2). All the values for the intercept, slope (CLR) and TTD calculated for nymphs reared under different photoperiods are significantly different for individuals from the same population, according to the $t$-test results (Table 2). Thus, the photoperiodic conditions significantly influenced the dependence of nymphal development on temperature in the linden-bug.

\section{DISCUSSION}

Firstly the results of this study confirm the findings of previous authors (Saunders, 1983, Numata et al., 1993) that the development of the linden-bug is accelerated when reared under typically short-day conditions at a temperature of $24^{\circ} \mathrm{C}$ and below (Figs 1, 2). Only individuals from the Pyatigorsk population took longer to develop when reared under a day-length of $14 \mathrm{~h}$ compared to one of $20 \mathrm{~h}$ at most temperatures (Fig. 1c). Presumably, the photoperiod 14 : 10 was not a short day for this southern population but appeared to be close to the critical photoperiod. This is why nymphs from the Pyatigorsk population reared under photoperiods of $20 \mathrm{~h}$ and $14 \mathrm{~h}$ and those from the Borisovka population reared under photoperiods of $20 \mathrm{~h}$ and $17 \mathrm{~h}$ responded very similarly (cf. Fig. 2c and Fig. 2d).

However, the most important result of this study is not the influence of photoperiod on development but the first demonstration of the effects of photoperiod on the thermal reaction norms for development or the thermal requirements for development in insects. The slope of the regression line of development rate on temperature (CLR) and the thermal threshold for nymphal development both decreased significantly with the shortening of day-length for individuals from all four $P$. apterus populations studied. That is nymphal development under short day conditions is less temperature dependent compared to development under long day conditions.

The results obtained for the Borisovka population (Fig. 2d) led us to conclude that the influence of photoperiod on the thermal reaction norm is more or less gradual. In other words, the shorter the day-length the smaller the slope of the regression line of development rate on temperature and the lower the thermal threshold for development. In this connection it is clear that photoperiods close to the critical one do not specifically retard the development compared to other day-lengths as concluded by previous authors (Saunders, 1983, Numata et al., 1993). Instead, their influence on the thermal requirements for development is more or less intermediate between the effects of typically long and typically short days and fit well into the whole range of photoperiodic effects in which the shortening day-length gradually decreases the CLR and TTD. However, if we compare the development rates at a single temperature, for example at $24^{\circ} \mathrm{C}$, we might conclude that the day-length of $17 \mathrm{~h}$ specifically retards development compared to longer and shorter days (Fig. 2d), as Saunders did (1983).

Nevertheless, the development of nymphs from Borisovka reared under a photoperiod of $17 \mathrm{~h}$, which is close to the critical photoperiod, appeared to take longer at all temperatures except $28^{\circ} \mathrm{C}$ (Fig. 1d). Thus, the interpretation proposed by Saunders (1983) that the retardation of

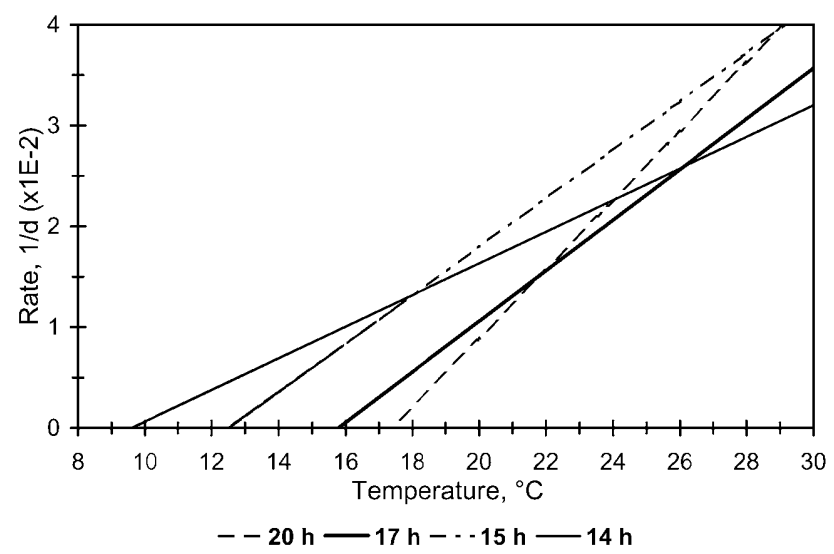

Fig. 3. Regression lines for development rate from oviposition to adult emergence on temperature under different photoperiods for Pyrrhocoris apterus from the Borisovka population. The regression line for the $15 \mathrm{~h}$ day-length was taken from the paper by Numata et al. (1993). 
A. Palomena prasina

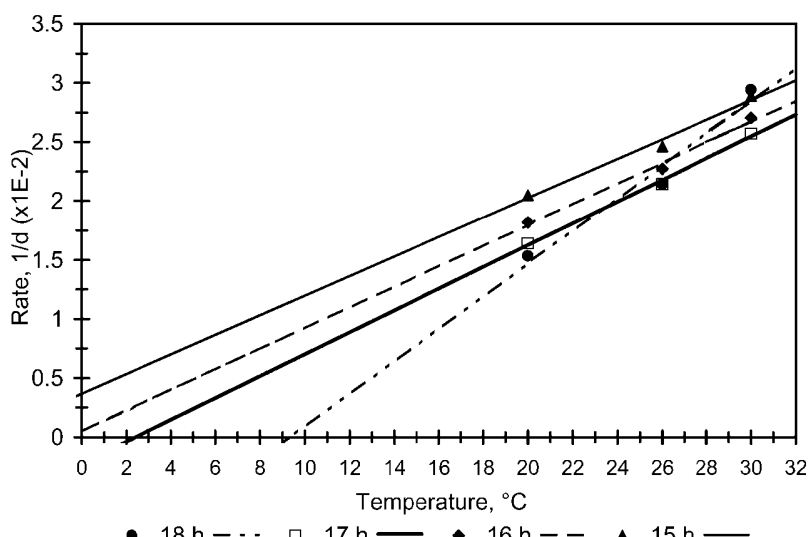

C. Nezara viridula

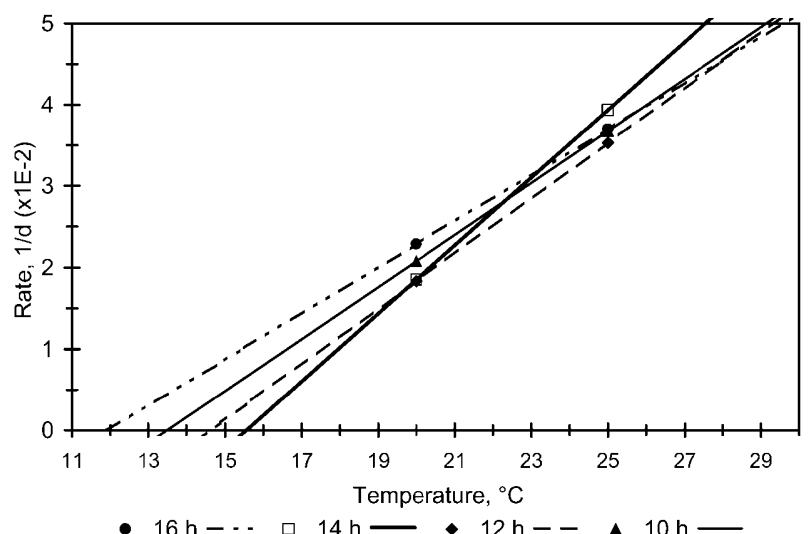

- $16 \mathrm{~h}-\cdots \square 14 \mathrm{~h} \longrightarrow$ - $12 \mathrm{~h}--$ \ $10 \mathrm{~h}-$

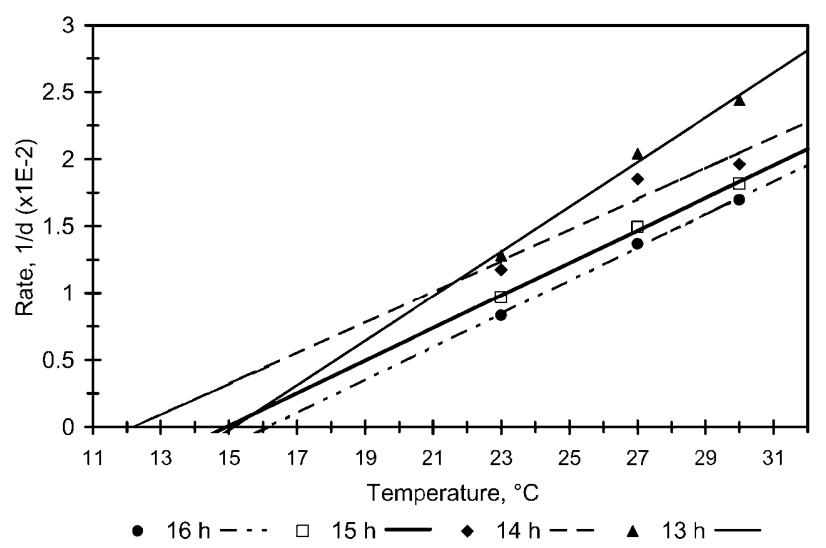

nymphal development under near-critical photoperiods might be adaptive, because it allows increased time for the accumulation of important inductive photocycles, may also be true.

The gradual effect of photoperiod on the thermal reaction norm is also supported by a comparison of our results with those published by Numata et al. (1993). These authors calculated the parameters of the linear regression of development rate on temperature for the same linden-bug population from Borisovka reared under a day-length of $15 \mathrm{~h}(\mathrm{y}=-3.00+0.24 \mathrm{x})$ and obtained a value for the $\operatorname{TTD}\left(12.5^{\circ} \mathrm{C}\right)$. However, they did not measure nymphal development time but the time from
B. Graphosoma lineatum

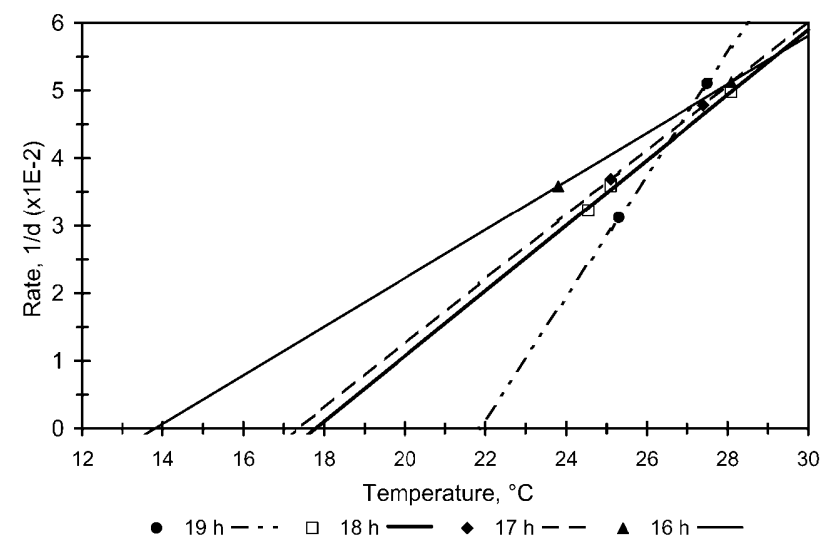

D. Orius strigicollis

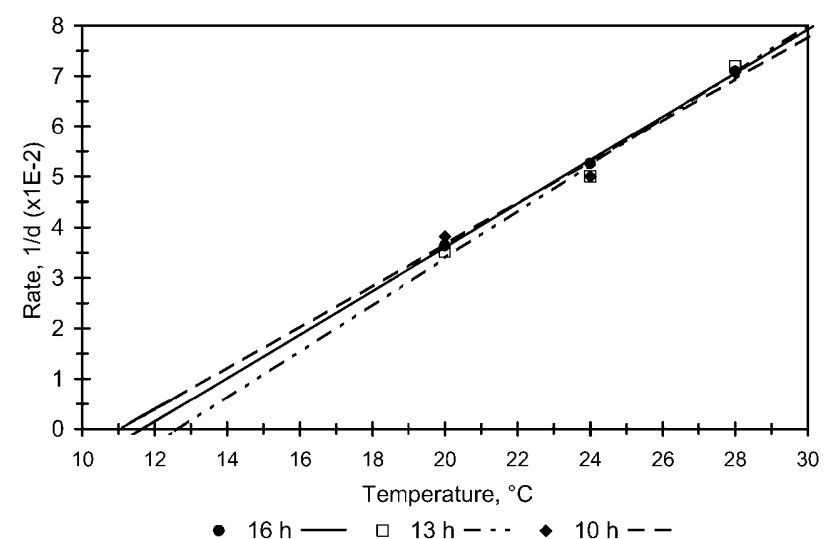

F. Melanoplus sanguinipes

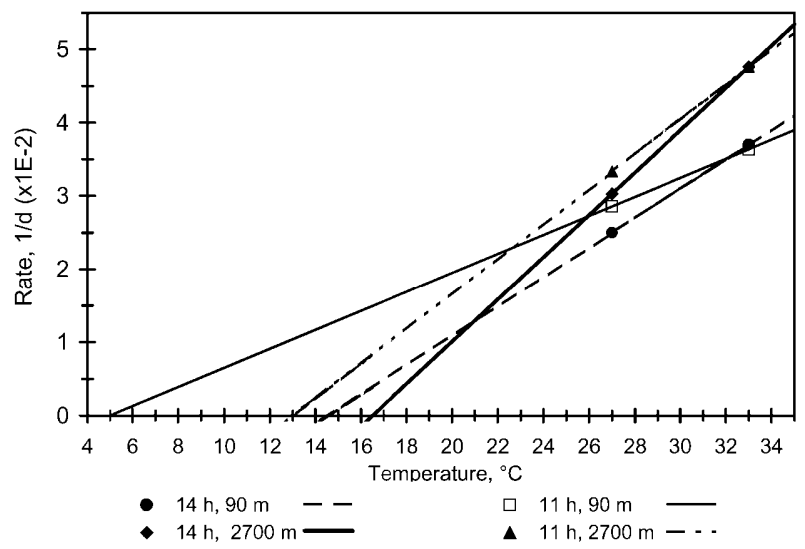

Fig. 4. Regression lines for development rate on temperature under different photoperiods calculated using the data from literature. A - nymphal development of the bug Palomena prasina (after Musolin \& Saulich, 1997); B - nymphal development of the bug Graphosoma lineatum (after Musolin \& Saulich, 1995); C - nymphal development of the bug Nezara viridula (after Musolin \& Numata, 2003); D the development of the bug Orius strigicollis from oviposition to adult emergence (after Musolin et al., 2004); E nymphal development of the cricket Pteronemobius fascipes (after Kidokoro \& Masaki, 1978); F - nymphal development of the grasshopper Melanoplus sanguinipes from two California populations: collected at altitudes of $90 \mathrm{~m}$ and 2700 m, respectively (after Dingle et al., 1990). 
egg oviposition to adult emergence. In order to have comparable results we have recalculated our data for the Borisovka population taking the period from oviposition to adult emergence as development time (Table 3). The regression line obtained by Numata et al. (1993) for a day-length of $15 \mathrm{~h}$ is clearly intermediate between our regression lines for 17 and $14 \mathrm{~h}$ (Fig. 3). The value of TTD estimated by these authors $\left(12.5^{\circ} \mathrm{C}\right)$ is also intermediate between the TTD values for $14 \mathrm{~h}\left(9.6^{\circ} \mathrm{C}\right)$ and $17 \mathrm{~h}$ $\left(15.8^{\circ} \mathrm{C}\right)$ derived from our results (Table 3, Fig. 3 ).

The effect of photoperiod on the thermal requirements for development of the linden-bug revealed in our study seems to be adaptive. The development times of nymphs reared under long-day photoperiods are shorter at relatively higher temperatures (above $24-25^{\circ} \mathrm{C}$ ) which might be advantageous at the height of summer when days are long and the weather is warm. The relatively high values of TTD associated with the higher dependence of development rate on temperature (higher CLR) are not disadvantageous in mid-summer because temperature is well above $17-18^{\circ} \mathrm{C}$ at that time of year. The retardation of nymphal development at near-critical photoperiods first observed by Saunders (1983) and confirmed by our results might also be adaptive. In fact, a longer development time might be advantageous if it enables the induction of diapause and thus prevents the production of progeny that have insufficient time to complete their development in autumn.

In contrast, at the end of summer when days are shorter and the weather cooler nymphs need to be able to develop faster at relatively low temperatures if they are to reach the adult stage, which is capable of overwintering. Therefore, the effect of short-day photoperiods, which make development less dependent on temperature, appears to be adaptive. Under short-day conditions linden-bug nymphs develop more slowly at relatively high temperatures and significantly faster at relatively low temperatures (below $24-25^{\circ} \mathrm{C}$ ). Moreover, the decrease in TTD values down to $9-12^{\circ} \mathrm{C}$ associated with the lower dependence of development rate on temperature (lower CLR) is also possibly advantageous at that time of year. Thus, linden-bug nymphs benefit from having their thermal requirements for development dependent on photoperiod throughout summer.

The only paper, in which the regression lines for development rate on temperature are presented for long-day and short-day conditions, is that of Nakamura (2002) on the bug, Dolycoris baccarum. The author depicts the regression lines in a figure but does not comment on the slight decrease in the slope and the lower TTD value when reared under short-day compared to long-day conditions.

In most previous studies only one temperature regime is used to reveal the difference in the duration of insect development under short and long-day conditions. But as our results indicate photoperiod can influence the thermal requirements for development in such a way that development might be accelerated under some temperatures but retarded under the others. Thus, it is important to use more than one temperature regime when investigating the influence of photoperiod on the development rate of insects.

In a few studies two and even three temperatures are used for studying the effect of photoperiod on development time. This is insufficient for a correct estimate of the thermal requirements for development (Campbell et al., 1974). Nevertheless, we tried to calculate the parameters of the linear regression of the development rate on temperature for these data in order to determine whether photoperiod affects the thermal reaction norms for development in other insect species.

For four bug species studied at 2-3 temperatures the photoperiod appears to influence on their thermal requirements for development (Fig. 4). In Graphosoma lineatum (Musolin \& Saulich, 1995) and Palomena prasina (Musolin \& Saulich, 1997) the effect of photoperiod appears to be the same as in P. apterus: the slopes of the regression lines gradually decrease as the days shorten which also results in a simultaneous decrease in the TTD value (Fig. 4a, b). At the same time in Nezara viridula (Musolin \& Numata, 2003) and Orius strigicollis (Musolin et al., 2004) the effects of photoperiod were evident but not so definite in their direction (Fig. 4c, d). Similarly the nymphal development of the cricket, Pteronemobius fascipes (Kidokoro \& Masaki, 1978): under 16 to $14 \mathrm{~h}$ day-lengths the values of CLR were the same but the TTD value gradually decreased from 16 to $12^{\circ} \mathrm{C}$, whereas the development of nymphs reared at daylength of $13 \mathrm{~h}$ was evidently more dependent on temperature (Fig. 4e). Finally, patterns very similar to those in $P$. apterus were found in two California populations of the grasshopper, Melanoplus sanguinipes studied by Dingle et al. (1990): the values of CLR and TTD appeared to be significantly lower when reared under a $11 \mathrm{~h}$ day-length compared to $14 \mathrm{~h}$ day-length (Fig. 4f).

TABLE 3. Parameters of linear regression of development rate on temperature and the values of the thermal threshold for development from oviposition to adult emergence of linden bugs from Borisovka when reared under different photoperiods.

\begin{tabular}{cccccccr}
\hline \multirow{2}{*}{ Photoperiod L : D } & \multirow{2}{*}{ Sample size } & \multicolumn{2}{c}{ Parameters of linear regression of development rate on temperature $\left(\times 10^{-2}\right)$} & \multirow{2}{*}{ TTD } & \multirow{2}{*}{ SE of TTD } \\
\cline { 3 - 6 } & & Intercept & SE of intercept & Slope & SE of slope & \\
\hline $20: 4$ & 120 & -5.981 & 0.233 & 0.3431 & 0.012 & 17.41 & 0.25 \\
$17: 7$ & 158 & -3.961 & 0.304 & 0.2511 & 0.010 & 15.81 & 0.33 \\
$14: 10$ & 137 & -1.511 & 0.264 & 0.1571 & 0.010 & 9.61 & 0.79 \\
\hline
\end{tabular}

Slope - the coefficient of linear regression of development rate on temperature (CLR); TTD - thermal threshold for development $\left({ }^{\circ} \mathrm{C}\right)$. The values of intercept, slope and TTD calculated for insects from the same population reared at different photoperiods are significantly different $(t$-test $)$ if marked with the same number $(\mathrm{p}<0.01-0.001)$. 
The results of experiments carried out at only three or particularly two temperatures are not fully conclusive. However, they unambiguously show that photoperiod affects the thermal requirements for development in many insects. This has been overlooked by previous researchers simply because nobody realized that the differences in the development time under various photoperiods might be due to changes in the thermal requirements for development.

Building upon the results of this and the previous studies by our group which have revealed quite definite differences in the thermal requirements for development associated with latitude (Kipyatkov \& Lopatina, 2002; Kipyatkov et al., 2004; Lopatina et al., 2002) or season (Kipyatkov et al., 2005), as well a thorough analysis of the literature, we came to an important conclusion. We suppose that the variation in development time observed in insects in different seasons, or when reared under different photoperiods or food regimes, or from different populations, latitudes, altitudes etc., are generally due to corresponding variation in the thermal reaction norms and more specifically to differences in the thermal requirements for development. These differences might be adaptive or presumably non-adaptive in some cases but they are always the result of modifications of the thermal reaction norms for development. Further research is needed to verify this conclusion.

One more question remains to be resolved in connection with the influence of photoperiod on nymphal development in bugs. Do photoperiods affect the thermal requirements for development of all nymphal instars equally, or are some of them more sensitive to photoperiod than the others? In the study by Conradi-Larsen \& Sømme, 1973 (Musolin \& Saulich, 1997) on the bug Dolycoris baccarum a slight retardation in nymphal development was observed under short day ( $8 \mathrm{~h})$ compared to long-day $(16 \mathrm{~h})$ conditions at a temperature of $21^{\circ} \mathrm{C}$. But the differences in development time were only significant for the second and the third nymphal instars. In another three bugs species, Palomena prasina, $P$. angulosa and Eysarcoris lewisi, short-day conditions resulted in an acceleration of nymphal development, which was most pronounced in the last two instars - the fourth and fifth (Musolin \& Saulich, 1997). Nothing is known of the influence of photoperiod on each of the five nymphal instars of the linden bug. This problem is worthy of further study.

ACKNOWLEDGEMENTS. The authors are very grateful to I. Hodek, A. Saulich and T. Volkovich for much advice on the laboratory culturing of the linden bug. We also thank I. Sokolova for her help with the experimental work. We also very greatly appreciate the detailed reviews and corrections to the manuscript made by two anonymous referees. This study was supported by the Russian Foundation of Basic Research (grants 03-04-48854 and 06-04-49383), as well as by The Council for Grants from the President of Russian Federation and for State Support of Leading Scientific Schools (grant 7130.2006.4).

\section{REFERENCES}

Campbell A., Fraser B.D., Gilbert N., Gutierrez A.P. \& MACKAUER M. 1974: Temperature requirements of some aphids and their parasites. J. Appl. Ecol. 11: 431-438.

DANKs H.V. 1987: Insect Dormancy: An Ecological Perspective. Biological Survey of Canada (Terrestrial Arthropods), Ottawa, ix +439 pp.

Dingle H., Mousseau T.A. \& Scott S.M. 1990: Altitudinal variation in life cycle syndromes of California populations of grasshopper, Melanoplus sanguinipes (F.). Oecologia 84: 199-206.

HoNĚK A. 1996a: Geographical variation in thermal requirements for insect development. Eur. J. Entomol. 93: 303-312.

HoNĚK A. 1996b: The relationship between thermal constants for insect development: a verification. Acta Soc. Zool. Bohem. 60: $115-152$.

HoněK A. \& Kocourek F. 1990: Temperature and development time in insects: a general relationship between thermal constants. Zool. Jb. Syst. 117: 401-439.

Kidokoro T. \& MASAKI S. 1978: Photoperiodic response in relation to variable voltinism in the ground cricket, Pteronemobius fascipes Walker (Orthoptera: Gryllidae). Jap. J. Ecol. 28: 291-298.

KipyatKov V.E. \& LopatinA E.B. 2002: Reaction norm in response to temperature may change to adapt rapid brood development to boreal and subarctic climates in Myrmica ants (Hymenoptera: Formicidae). Eur. J. Entomol. 99: 197-208.

Kipyatkov V.E., Lopatina E.B., Imamgaliev A.A. \& Shirokova L.A. 2004: Influence of temperature on the rearing of the first brood by founding queens of the ant Lasius niger L. (Hymenoptera, Formicidae): latitudinal variation of the reaction norm. Zh. Evol. Biokhim. Fisiol. 40: 134-141 [in Russian, English abstr.].

Kipyatkov V., Lopatina E. \& Imamgaliev A. 2005: Duration and thermal reaction norms of development are significantly different in winter and summer brood pupae of the ants Myrmica rubra Linnaeus, 1758 and M. ruginodis Nylander, 1846 (Hymenoptera, Formicidae). Myrmecol. Nachr. 7: 69-76.

Lopatina E.B., Imamgaliev A.A. \& KipyatKov V.E. 2002: Latitudinal variation of duration and thermal lability of pupal development in three ant species of the genus Myrmica Latr. (Hymenoptera, Formicidae). Entomol. Obozr. 81: 265-275 [in Russian, English abstr.].

Lamb R.J., MacKay P.A. \& Gerber G.H. 1987: Are development and growth of pea aphids, Acyrthosiphon pisum, in North America adapted to local temperatures? Oecologia 72: 170-177.

Musolin D.L. \& Numata H. 2003: Photoperiodic and temperature control of diapause induction and colour change in the southern green stink bug Nezara viridula. Physiol. Entomol. 28: $65-74$.

Musolin D.L. \& SAulich A.H. 1995: Factorial regulation of the seasonal cycle of the stink bug Graphosoma lineatum L. (Heteroptera, Pentatomidae). I. Temperature and photoperiodic responses. Entomol. Obozr. 74: 736-743 [in Russian, English abstr.]. [Translation in Entomol. Rev. 1996, 75(9): 84-93.]

Musolin D.L. \& SAulich A.H. 1997: Photoperiodic control of nymphal growth in true bugs (Heteroptera) Zool. Zh. 76: 530-542 [in Russian, English abstr.]. [Translation in Entomol. Rev. 1997, 77(6): 768-780.]

Musolin D.L., Tsytsulina K. \& Ito K. 2004: Photoperiodic and temperature control of reproductive diapause induction in the predatory bug Orius strigicollis (Heteroptera: Anthocoridae) and its implications for biological control. Biol. Contr. 31: 91-98. 
NAKAmuRA K. 2002: Effect of photoperiod on the sizetemperature relationship in a pentatomid bug, Dolycoris baccarum. J. Therm. Biol. 27: 541-546.

Numata H., Saulich A.H. \& Volkovich T.A. 1993: Photoperiodic responses of linden bug, Pyrrhocoris apterus, under conditions of constant temperature and under thermoperiodic conditions. Zool. Sci. 10: 521-527.

Ratte H.T. 1985: Temperature and insect development. In Hoffmann K.H. (ed.): Environmental Physiology and Biochemistry of Insects. Springer, Berlin, Heidelberg, New York, Tokyo, pp. 33-66.

SAUNDERS D.S. 1983: A diapause induction-termination asymmetry in the photoperiodic responses of the linden bug, Pyrrhocoris apterus and an effect of near-critical photoperiods on the development. J. Insect Physiol. 29: 399-405.
Tauber C.A., Tauber M.J. \& Nechols J.R. 1987: Thermal requirements for development in Chrysopa oculata: a geographically stable trait. Ecology 68: 1479-1487.

Tauber C.A., Tauber M.J., Gollands B., Wright R.J. \& OBRYCKI J.J. 1988: Preimaginal development and reproductive responses to temperature in two populations of the Colorado potato beetle (Coleoptera: Chrysomelidae). Ann. Entomol. Soc. Am. 81: 755-763.

VolKovich T.A. \& GoRYshin N.I. 1978: Evaluation and accumulation of photoperiodic information in Pyrrhocoris apterus L. (Hemiptera, Pyrrhocoridae) during the induction of oviposition. Zool. Zh. 57: 46-55 [in Russian, English abstr.].

Received April 27, 2006; revised and accepted September 27, 2006 